\title{
$\mathrm{XRD}$ 와 XPS를 사용한 산화아연 박막의 결함형성과 산소연관 결합사이의 상관성
}

\author{
오데레사 ${ }^{\dagger}$ \\ 청주대학교 반도체공학과
}

\section{Correlation between Oxygen Related Bonds and Defects Formation in ZnO Thin Films by Using X-ray Diffraction and X-ray Photoelectron Spectroscopy}

\author{
Teresa $\mathrm{Oh}^{\dagger}$ \\ Department of Semiconductor Engineering, Cheongju University
}

(2013년 8월 3일 접수 : 2013년 9월 24일 최종수정 : 2013년 9월 30일 채택)

\begin{abstract}
To observe the formation of defects at the interface between an oxide semiconductor and $\mathrm{SiO}_{2}, \mathrm{ZnO}$ was prepared on $\mathrm{SiO}_{2}$ with various oxygen gas flow rates by RF magnetron sputtering deposition. The crystallinity of $\mathrm{ZnO}$ depends on the characteristic of the surface of the substrate. The crystallinity of $\mathrm{ZnO}$ on a $\mathrm{Si}$ wafer increased due to the activation of ionic interactions after an annealing process, whereas that of $\mathrm{ZnO}$ on $\mathrm{SiO}_{2}$ changed due to the various types of defects which had formed as a result of the deposition conditions and the annealing process. To observe the chemical shift to understand of defect deformations at the interface between the $\mathrm{ZnO}$ and $\mathrm{SiO}_{2}$, the $\mathrm{O}$ 1s electron spectra were convoluted into three sub-peaks by a Gaussian fitting. The $\mathrm{O} 1 \mathrm{~s}$ electron spectra consisted of three peaks as metal oxygen (at $530.5 \mathrm{eV}$ ), $\mathrm{O}^{2-}$ ions in an oxygendeficient region (at $531.66 \mathrm{eV}$ ) and $\mathrm{OH}$ bonding (at $532.5 \mathrm{eV}$ ). In view of the crystallinity from the peak (103) in the XRD pattern, the metal oxygen increased with a decrease in the crystallinity. However, the low FWHM (full width at half maximum) at the (103) plane caused by the high crystallinity depended on the increment of the oxygen vacancies at $531.66 \mathrm{eV}$ due to the generation of $\mathrm{O}^{2-}$ ions in the oxygen-deficient region formed by thermal activation energy.
\end{abstract}

Key words $\mathrm{ZnO}$, defect, metal oxygen, $\mathrm{O}$ 1s orbital spectra, oxygen vacancy.

\section{1. 서 론}

가장 널리 사용되는 투명전극으로 ITO(Indium Tin Oxide)는 인듐의 독성, 저온 증착의 어려움, 스퍼터링시 음이온 충격에 의한 막 손상으로 저항이 증가하며, 디 스플레이의 투명전극으로 사용될 경우 $400{ }^{\circ} \mathrm{C}$ 정도의 높 은 온도에 장시간 노출시 열화로 인한 광학적 특성이 변 한다. ${ }^{1,2)} \mathrm{ZnO}$ 계열의 산화물반도체는 이러한 문제 해결의 대안으로 제시되었다. $\mathrm{ZnO}$ 는 넓은 밴드갭에너지 $(3.3 \mathrm{eV})$ 와 높은 엑시톤 결합 에너지 $(60 \mathrm{meV})$ 를 가지며 대면적 합성이 가능하여 ultra violet light 센서, light emitting
$\operatorname{diode}(\mathrm{LED})$ 그리고 디스플레이 등에 쓰여지며, 광학적 특 성의 개선을 위하여 효율을 향상 시키려는 연구가 진행 되고 있다. ${ }^{3-6)}$ 일반적으로 $\mathrm{ZnO}$ 는 격자틈새 $\mathrm{Zn}$ 이온 $\left(\mathrm{Zni}^{2+}\right)$ 이나 산소 빈자리이온 $\left(\mathrm{Vo}^{2+}\right)$ 등과 같은 자연적인 도너 이 온의 존재로 인한 n-형 전도특성을 나타낸다. 또한 억셉 터 이온의 낮은 도핑 용해도, 결정 내에서 도핑된 억셉 터의 복합체 형성, 그리고 도핑된 도펀트가 격자 틈새 자 리에 위치함으로써 발생하는 전기적인 비활성화 는 p-형 전도특성의 $\mathrm{ZnO}$ 박막의 형성을 어렵게 한다. $\mathrm{ZnO}$ 내 생 성되는 결함으로써 deep impurity level과 native defects (O vacancy, $\mathrm{Zn}$ interstitial, $\mathrm{Zn}$ anti-site)는 자연적으로

\footnotetext{
'Corresponding author

E-Mail : teresa@cju.ac.kr (Teresa Oh, Cheongju Univ.)
}

(C) Materials Research Society of Korea, All rights reserved.

This is an Open-Access article distributed under the terms of the Creative Commons Attribution Non-Commercial License (http://creativecommons.org/licenses/by-nc/3.0) which permits unrestricted non-commercial use, distribution, and reproduction in any medium, provided the original work is properly cited. 
$\mathrm{ZnO}$ 가 n-type 특성을 가지게 만들 뿐만 아니라 hole을 상쇄시켜 p-type 반도 특성확보를 어렵게 하는 것으로 알 려져 있다. ${ }^{7,8)}$ 고저항체로서 높은 비저항을 갖는 벌크 상 태의 $\mathrm{ZnO}$ 는 박막화 과정에서 $\mathrm{Zn}$ 과 $\mathrm{O}$ 의 비율이 $1: 1$ 을 벗어나 비화학양론적인 구조를 갖는다. 따라서 $\mathrm{Zn}$ 침입 형 원자나 산소공공과 같은 결합들을 결정 내에 포함하 고 있으며, 이들 결정 결함들은 이온화 반응을 거쳐 전 자를 생성하여 전기전도에 기여하게 된다. 여기에 인위 적으로 도너 불순물을 도핑하여 $\mathrm{ZnO}$ 입자내의 도너 상 태 밀도를 증가시켜 전기적 특성을 향상시킨다. 그러나 투명 전도성 박막은 기판 물질의 특성에 따라서 결정성 이 달라지며, 격자상수 차이로 인한 접합부분의 계면저 항이 높아 효율이 떨어지고 따라서 이동도가 떨어지는 단점이 있다. ${ }^{9-11)}$ 그래서 이동도를 높이기 위해서는 서로 다른 물질이 만나는 계면에서 결정성의 불일치를 최소 화하도록 해야 한다. $\mathrm{ZnO}$ 박막에서 산소에 의한 결함 의 형성은 박막내의 deep impurity level과 연관되어 있 으며, 결정성이 떨어지는 원인으로 알려져 있다. $\mathrm{ZnO}$ 박 막을 이용하여 투명전극으로서 뿐만 아니라 투명 전도 성 산화물(transparent conducting oxide: TCO) 박막 트 랜지스터(transparent thin film transistors: TTFTs)에도 적용하여 연구되고 있다. 반도체 전자소자의 동작원리는 주로 $\mathrm{SiO}_{2}$ 산화 막과의 계면에 의한 결함의 증가로 인 하여 저항이 증가한다. 따라서 전자소자 이동도의 향상 과 계면저항을 감소시키기 위한 연구가 필요하며, 산소 와 관련된 결함으로 산소공공과 금속성 원자주변에 존 재하는 산소이온에 의한 격자틈새 $\mathrm{Zn}$ 이온 $\left(\mathrm{Zni}^{2+}\right)$ 이나 산 소 빈자리이온 $\left(\mathrm{Vo}^{2+}\right)$ 등과 같은 자연적인 도너 이온들과 관련된 결함들이 결정성에 미치는 영향에 대한 연구를 통하여 투명반도체를 이용한 전자소자의 이동도 향상에 기여할 수 있다. ${ }^{12-14)}$ 전자소자의 전자방사능력은 접합계 면의 결함들과 관련이 있으며, 즉 전자소자의 이동도에 영향을 주고 있다. ${ }^{15)}$ 그러므로 다양한 형태의 결함들이 생성원인과 효과에 대한 명확한 연구가 필요하다.

본 연구에서 $\mathrm{ZnO}$ 산화물 반도체 물질의 계면 특성의 변화에 따라 생성되는 결함의 특성을 조사하기 위해서 $\mathrm{ZnO}$ 를 $\mathrm{RF}$ 마그네트론 스퍼터링법을 이용하여 박막을 성 장시켰으며, 열처리를 통하여 계면의 특성을 변화시켰다. 모든 박막들은 XRD, XPS를 이용하여 물리적 화학적인 특성을 분석하였다. 서로 다른 박막들 사이에서 생성되 는 결합의 특성과 박막의 물리적 화학적 특성 변화 사 이의 상관성을 분석하였다. $\mathrm{ZnO}$ 박막의 결함들은 산소 공공에 의한 결합 및 metal oxygen(Zn interstitial)에 의 한 결함, $\mathrm{OH}$ 그룹에 의한 결함들이 있으며, $\mathrm{SiO}_{2} / \mathrm{Si}$ 기 판 위에 여러 가지 조건에서 처리된 $\mathrm{ZnO}$ 박막과의 상 관성에 대하여 분석하였다.
Table 1. Experimental conditions.

\begin{tabular}{cc}
\hline Target & $\mathrm{ZnO}$ \\
Substrate & $\mathrm{p}-\mathrm{Si}$ and $\mathrm{SiO}_{2} / \mathrm{Si}$ \\
Oxygen gas flow & $30,50,70 \mathrm{sccm}$ \\
Deposition time & 10 minute \\
Annealing & Vacuum, $300^{\circ} \mathrm{C}$ \\
Deposition & $\mathrm{RF}$ magnetron sputtering \\
Analyzer & XRD, XPS \\
\hline
\end{tabular}

\section{2. 실험 방법}

$\mathrm{p}-\mathrm{Si}$ 기판은 유기물과 산화물을 제거하기 위해 $\mathrm{RCA}$ 클 리닝과정을 거쳐 준비하였다. 기판의 특성과 열처리효과 에 대한 영향을 알아보기 위해서 $\mathrm{ZnO}$ 박막은 radio frequency(RF) magnetron sputtering방법으로 실리콘 기판과 $\mathrm{SiO}^{2} / \mathrm{Si}$ 기판 위에 증착 하였으며, 300 도에서 저 진공 중 에서 30분간 열처리를 실시하였다. 타겟은 $\mathrm{ZnO}(99.999 \%$ $\mathrm{wt}$ ) 을 사용하였으며, 초기 압력은 $4.5 \times 10^{-5} \mathrm{Torr}$ 이고, 증 착 중 압력은 $1.2 \sim 1.3 \times 10^{-3}$ Torr 였다. 플라즈마 반응을 위해서 산소를 $30,50,70 \mathrm{sccm}$ 을 각각 10 분동안 흘려주 었으며, $\mathrm{RF}$ 파워는 $13.56 \mathrm{MHz}, 100 \mathrm{~W}$ 였다. $\mathrm{ZnO}$ 박막 의 특성과 열처리 온도에 따른 특성을 분석하기 위해서 $\mathrm{XRD}(\mathrm{X}$-ray diffraction, XDS2000)와 XPS(X-ray photoelectron spectroscopy, ESCALAB210)를 이용하여 분석 하였다.

\section{3. 결과 및 고찰}

$\mathrm{ZnO}$ 기반의 산화물 반도체가 트랜지스터에 적용 되어 지고 있으며, $\mathrm{ZnO}$ 박막의 경우 결정성이 전도도와 밀 접한 관계가 있다. 따라서 박막의 기판의존성을 살펴보 기 위해서 $\mathrm{Si}$ 웨이퍼와 $\mathrm{SiO}_{2} / \mathrm{Si}$ 기판 위에서의 결정성을 분석하였다.

Fig. 1은 실리콘 웨이퍼 위에 증착한 $\mathrm{ZnO}$ 박막의 $\mathrm{XRD}$ 데이터를 나타내고 있다. Fig. 1(a)에서 $\mathrm{ZnO} / \mathrm{Si}$ 의 XRD 패턴은 $\mathrm{ZnO}$ (002)와 $\mathrm{ZnO}$ (103) 면에 대하여 $34^{\circ}$ 와 $62^{\circ}$ 근처에서 강한 peak이 보여지는 Wurtzite 구조의 결정성 의 박막임을 알 수 있게 한다. Fig. 1(b)는 $\mathrm{ZnO}$ 증착 후 진공 중에서 온도에 따른 $(002) /(103)$ 의 비를 나타내 며, 온도가 올라갈수록 $(002) /(103)$ 의 비가 커지면서 결 정성이 더 높아지는 것을 알 수 있다. 기판의 종류에 따 른 특성을 알아보기 위해서 $\mathrm{SiO}_{2} / \mathrm{Si}$ 위에 증착한 $\mathrm{ZnO}$ 박막의 XRD 특성을 살펴보았다.

Fig. 2는 $\mathrm{SiO}_{2} / \mathrm{Si}$ 위에 증착한 $\mathrm{ZnO}$ 박막의 XRD 데이 터이다. $\mathrm{ZnO}$ 를 증착하기 위하여 산소를 $30 \mathrm{sccm}, 50$ $\mathrm{sccm}$ 그리고 $70 \mathrm{sccm}$ 을 흘려주었다. 그림 (a), (b), (c) 

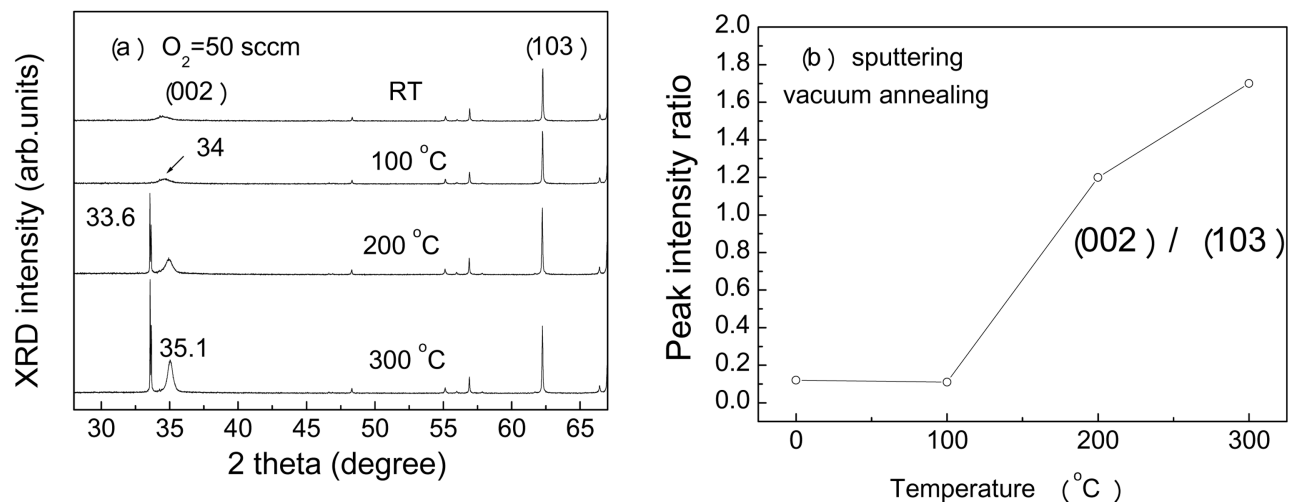

Fig. 1. XRD diffraction patterns of the $\mathrm{ZnO}$ film deposited on $\mathrm{Si}$ wafer as a function of annealing temperature.
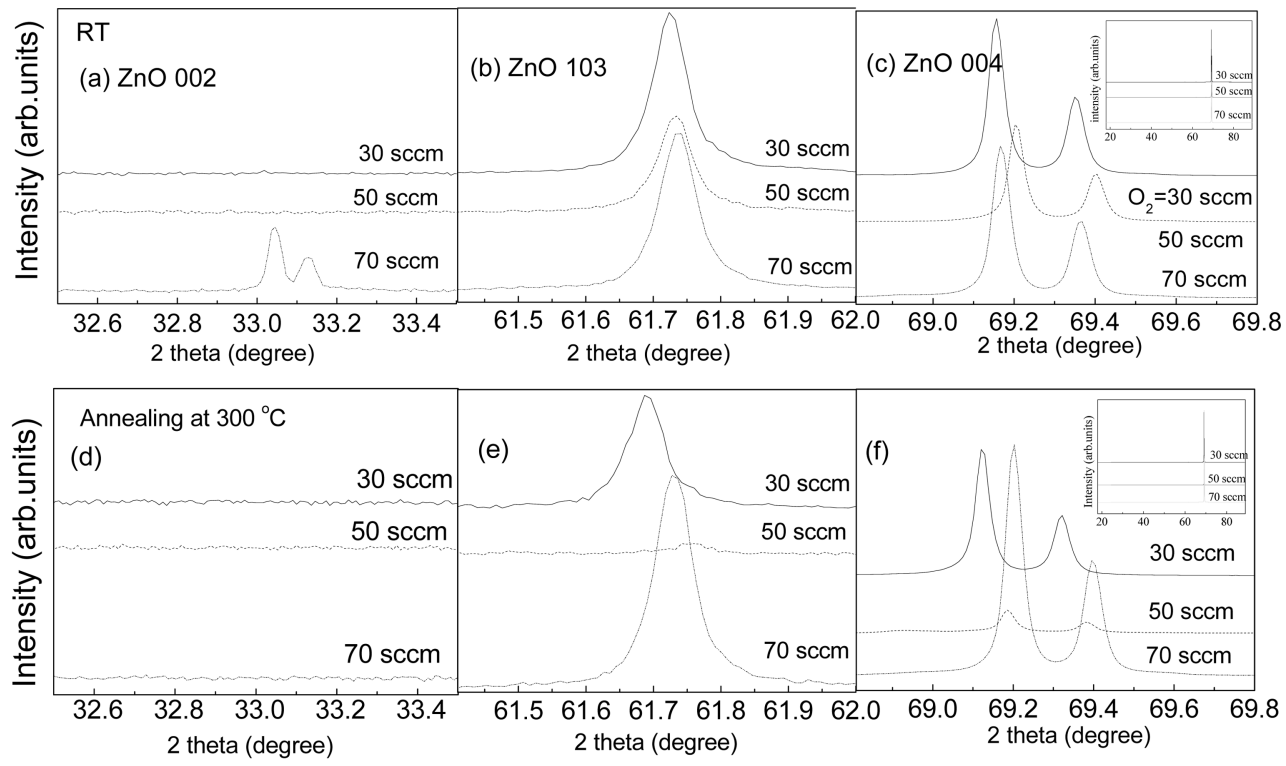

Fig. 2. XRD patterns at $33.4^{\circ}, 61.7^{\circ}$ and $69.2^{\circ}$ of deposited and annealed $\mathrm{ZnO}$ films prepared on $\mathrm{SiO}_{2} / \mathrm{Si}$ substrate by pulsed laser deposition.
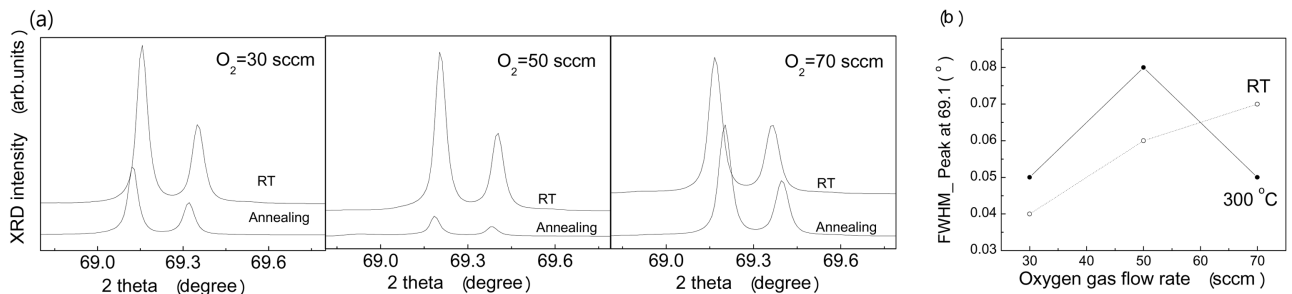

Fig. 3. $\mathrm{XRD}$ difractogram of $\mathrm{ZnO} / \mathrm{SiO}_{2} / \mathrm{Si}$ films, (a) comparison with deposited and annealed films, (b) $\mathrm{FWHM}$ at $69.1^{\circ}$ of $\mathrm{ZnO}$ grown at RT and $300{ }^{\circ} \mathrm{C}$ during the post annealing process.

는 $\mathrm{ZnO}$ 를 증착한 박막의 특성이며, (d), (e), (f)는 열처 리한 후의 박막의 특성을 나타낸다. Fig. 2(c)와 Fig. 2(f)에 삽입된 그림을 보면 $69^{\circ}$ 근처에서 강한 peak이 나 타나고 $34^{\circ}$ 와 $62^{\circ}$ 근처에서는 상대적으로 peak의 강도가 약하여 peak을 확인할 수 없는 것을 알 수 있다. $\mathrm{SiO}_{2}$ 과 $\mathrm{ZnO}$ 박막 사이에서 생긴 결합에 의한 결자상수 불 일치에 의하여 결정성이 많이 없어진 것을 알 수 있다.
Fig. 2(a)에서 산소 $70 \mathrm{sccm}$ 의 유량에서는 $34^{\circ}$ 근처에 서 peak이 생성된 것으로 보아 반응가스인 산소의 양이 많을수록 결정성장이 잘 이루어지는 것을 알 수 있다. 또한 실리콘 위에서 $\mathrm{ZnO}$ 는 $33.6^{\circ}, 34^{\circ}, 35.1^{\circ}$ 에서 peak 이 나타났지만 $\mathrm{SiO}_{2}$ 위에 증착한 $\mathrm{ZnO}$ 에서는 $33.1^{\circ}$ 으로 peak의 위치가 낮은 쪽으로 이동하였다. 그러므로 $\mathrm{ZnO}$ 박막은 $\mathrm{SiO}_{2}$ 위에서 결정성이 낮아지면서 계면에서 많 
은 결함들이 존재한다는 것을 알 수 있다. Fig. 2(b)와 Fig. 2(e)에서 $61^{\circ}$ 근처에서는 열처리 후 산소의 유량이 많 은 $\mathrm{ZnO}$ 박막에서 높은 쪽으로 이동하는 것으로 보아 역 시 산소의 유량이 많은 경우 결정성이 상대적으로 우수 해진다. Fig. 2(c)와 Fig. 2(f)에서도 $61^{\circ}$ 근처에서는 열처 리 후 산소의 유량이 많은 경우 peak이 높은 쪽으로 이 동하는 것으로 보아 상대적으로 결정성이 우수해진다.

Fig. 3은 열처리 후 산소의 유량비에 따른 $\mathrm{ZnO}$ 박막 의 peak의 변화를 나타내는 것으로 반측 폭의 변화를 알 수 있다. Fig. 3(b)로부터 산소의 유량이 많은 $70 \mathrm{sccm}$ 인 박막에서 반측 폭이 감소하였으며, 이러한 특성은 결 정성이 더욱 좋아졌다는 것을 의미한다. 특히 산소유량 이 $50 \mathrm{sccm}$ 인 경우에서 열처리 후 peak이 약해지거나 없 어지는 현상이 나타나서 비정질 특성이 나타나는 현상 에서 XPS에서 산소관련 데이터의 변화에 대하여 살펴 보았다.

Fig. 4는 $\mathrm{SiO}_{2} / \mathrm{Si}$ 위에 증착한 $\mathrm{ZnO}$ 박막의 300 도 열 처리 후의 $531 \mathrm{eV}$ 근처의 $\mathrm{O} 1 \mathrm{~s}$ 오비탈 스펙트라의 변 화를 나타내고 있다. $\mathrm{ZnO}$ 의 본래의 결합으로서 산소공 공은 산소의 유량비나 열처리 과정에서 그 함량비가 변 하는 것을 알 수 있다. Fig. 4(a)에서 보듯이 O 1s 결합 에너지는 가우시안 방법에 의해 3 가지 결합이 존재하는 디컨벌류션 방법을 통하여 금속성 원자주변에 존재하는 산소이온에 의한 metal oxygen(Zn interstitial)과 산소결핍 반응에 의한 산소공공(oxygen vacancy)과 표면에서 산소 와의 결합에 의한 $\mathrm{OH}$ 결합 3 가지 결합으로 구성된다. 산 소의 유량이 많을수록 $\mathrm{O} 1 \mathrm{~s}$ 결합에너지의 위치는 높은 쪽으로 이동하고 있다. 이온화 과정 중에 나타나는 metal oxygen으로서 서로 다른 원소들간의 간극은 이온결합이
이루어진 상태가 아니기 때문에 결합길이는 최대한 멀 리 떨어져 있고 상호연관성이 미약하여 결합에너지가 작 아진다고도 할 수 있다. XRD에서 보았듯이 $50 \mathrm{sccm}$ 샘 플과 $70 \mathrm{sccm}$ 샘플의 열처리 후의 결과는 다른 양상을 나타내는 것을 확인하였듯이 Fig. 4(b), (c), (e), (f)에서 도 마찬가지였다. Fig. 4(c), (e)와 같이 비정질 특성이 증가하는 박막에서 metal oxygen peak의 상대적인 면적 이 증가하였고 반측 폭이 증가하였다. 그러나 Fig. 4(b), (f)에서와 같이 상대적인 결정성이 증가하는 박막에서 peak은 높은 결합에너지 쪽으로 이동하면서 반측 폭은 감 소하였다. 따라서 $\mathrm{ZnO}$ 박막은 결합이 증가할수록 결정 성이 감소하고 $\mathrm{XRD}$ 나 XPS분석에서 낮은 각도, 낮은 결 합에너지 방향으로 이동하고 반측 폭은 서서히 증가한 다는 것을 알 수 있다. 이렇게 결정성이 감소하는 이유 는 전자를 많이 갖는 주변의 금속원소에 의한 산소와의 이온결합이 증가하기 때문이며, $\mathrm{SiO}_{2} / \mathrm{Si}$ 위에 증착한 $\mathrm{ZnO}$ 박막은 $\mathrm{SiO}_{2}$ 표면에서 전자와 홀에 의한 이온결합이 증 가하면서 많은 결합들을 포함하게 된다는 것을 확인할 수 있다. $50 \mathrm{sccm}$ 의 샘플인 경우 열처리 후 결정성이 감 소하나 $70 \mathrm{sccm}$ 인 경우 결정성이 오히려 증가하여 전자 소자 제작에 좋은 특성을 갖는 것을 알 수 있다. 따라 서 전자소자에 적합한 특성으로 $\mathrm{ZnO}$ 을 증착하는 산소의 유량비나 열처리 온도에 대한 최적화 조건을 찾아내는 것이 중요하다.

Fig. 5 는 $\mathrm{SiO}_{2} / \mathrm{Si}$ 위에 증착한 $\mathrm{ZnO}$ 박막의 300 도 열 처리 후의 $1021.7 \mathrm{eV}$ 근처의 $\mathrm{Zn} 2 \mathrm{p}$ 결합에너지에 대한 분석 데이터이다.

Fig. 5(a)는 산소의 유량이 증가할수록 결합에너지의 위 치가 높아지고 있다. 열처리를 하게 되면 Fig. 5(b)에서
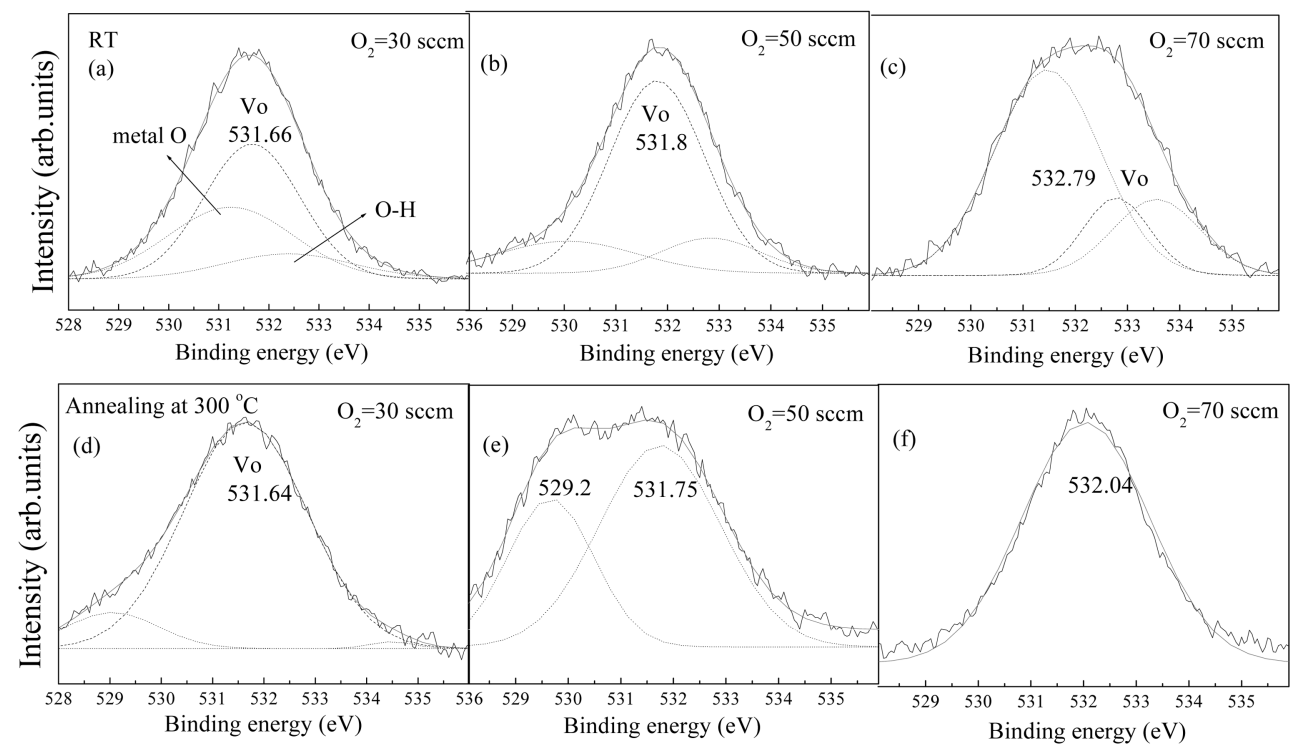

Fig. 4. O 1s XPS spectra of $\mathrm{ZnO}$ grown at $\mathrm{RT}$ and $300{ }^{\circ} \mathrm{C}$ post annealing. 

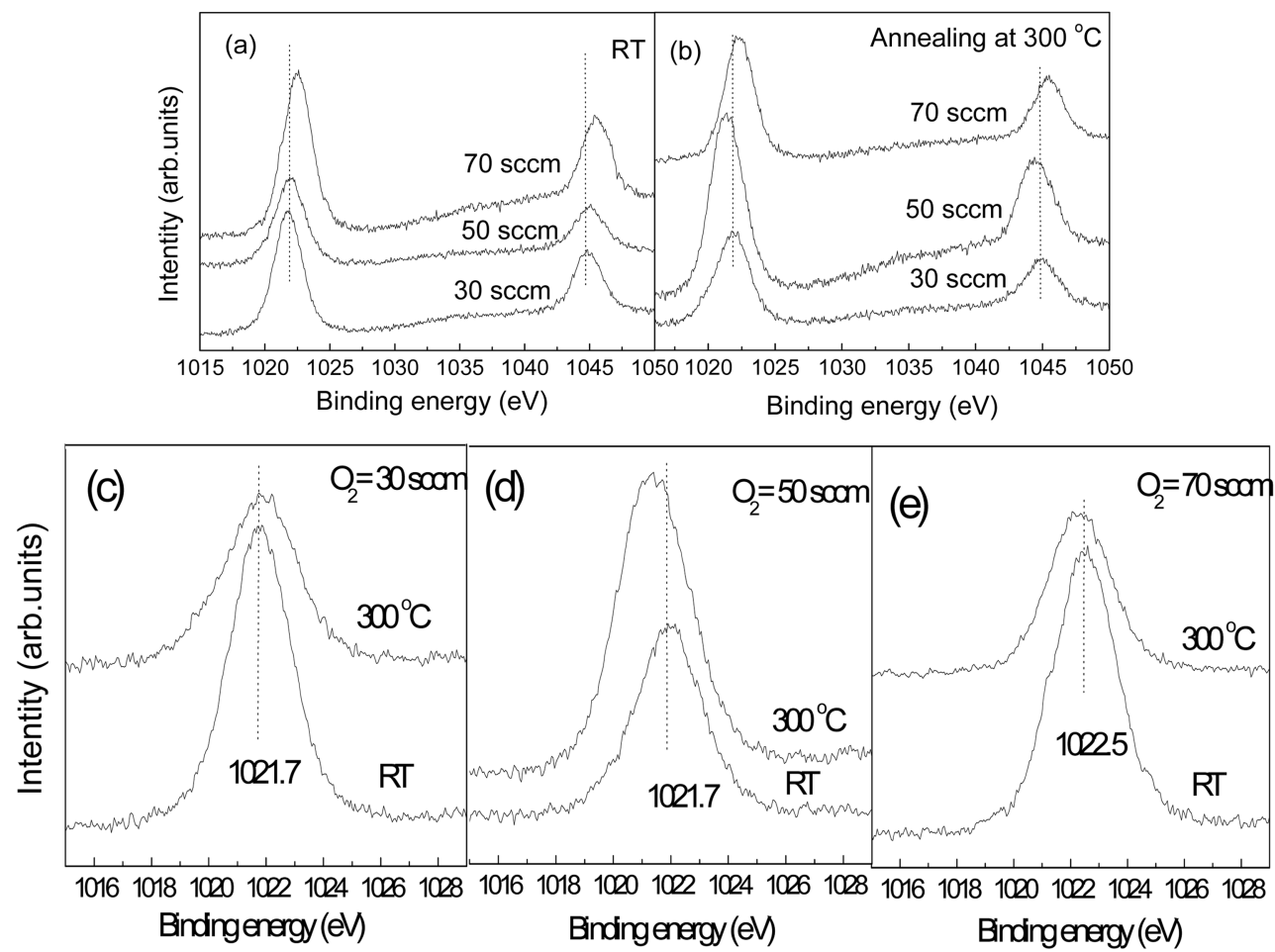

Fig. 5. $\mathrm{Zn} 2 \mathrm{p}$ XPS spectrum of $\mathrm{ZnO}$ films with various oxygen pressure and after annealed at $300{ }^{\circ} \mathrm{C}$, (a) as deposited films, (b) annealed films, comparison between RT and annealing treatment at samples with (c) $\mathrm{O}_{2}=30 \mathrm{sccm}$, (d) $\mathrm{O}_{2}=50 \mathrm{sccm}$, (e) $\mathrm{O}_{2}=70 \mathrm{sccm}$.
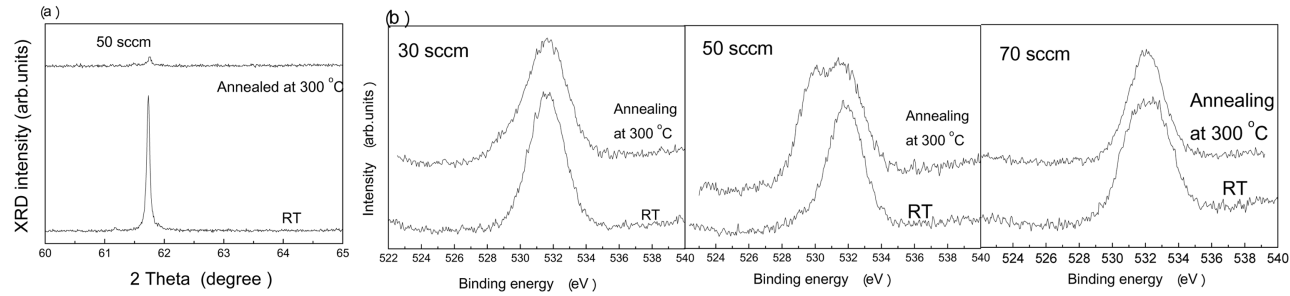

Fig. 6. Correlation between $61.7^{\circ}$ in XRD difractogram and in O 1s XPS spectra after annealing in ZnO with oxygen pressure of 50 sccm such as the disordering, (a) $61.7^{\circ}$ in XRD, (b) O 1s XPS spectra.

보듯이 결정성이 낮아지는 $50 \mathrm{sccm}$ 샘플에서는 결합에너 지 위치가 낮아지면서 peak의 강도가 넓고 커진다. 그 러나 결정성이 높아지는 $70 \mathrm{sccm}$ 샘플에서는 결합에너지 위치가 높아지면서 peak의 강도는 작아진다. Fig. 5(c), (d), (e)는 각각의 샘플에 대한 열처리 후 비교를 나타 낸다. $\mathrm{ZnO}$ 박막은 $1021.7 \mathrm{eV}$ 에서 $\mathrm{Zn} 2 \mathrm{p}$ peak이 나타나 며, 산소의 유량이 많은 샘플에서 결정성이 우수해지면서 $1021.7 \mathrm{eV}$ 보다 높은 결합에너지 쪽으로 이동하는 것을 확 인하였다. 다음 수식은 전자와 홀의 이온결합을 통하여 $\mathrm{ZnO}$ 결합을 이루거나 산소공공 결합을 나타내고 있다.

$$
Z n-O \leftrightarrow Z n^{2+}+O^{2-} \leftrightarrow V_{0}
$$

또한 $\mathrm{ZnO}$ 타겟에서 스터퍼링에 의한 플라즈마 에너지 로부터 이온화과정을 거쳐서 산소공공의 결함을 만들어
내는 과정을 설명하고 있기도 하다.

Fig. 6은 산소의 유량이 $50 \mathrm{sccm}$ 인 샘플에서 열처리효 과에 대한 $\mathrm{XRD}$ 와 $\mathrm{O} 1 \mathrm{~s}$ 결합에너지를 나타내고 있으며, $\mathrm{XRD}$ 분석에서 열처리 후 비정질 특성을 나타내며, XPS 분석에서 metal oxygen( $\mathrm{Zn}$ interstitial)의 증가에 의하여 $\mathrm{O} 1 \mathrm{~s}$ peak이 낮은 쪽으로 이동하고 있으며, 반측 폭도 증가하는 것을 보여준다.

\section{4. 결 론}

광학소자에 많이 이용되고 있는 투명 전도성 산화막인 $\mathrm{ZnO}$ 박막을 스퍼터링 방법으로 증착하고 열처리를 하여 산소공공과 결정성과의 상관성을 조사하였다. 수 $\mathrm{nm}$ 수 준으로 박막의 두께가 얇아질수록 전자소자의 전기적인 특성은 계면에서 생기는 결함들에 의한 의존도가 높다. 
따라서 결정성을 확인할 수 있는 $\mathrm{XRD}$ 분석이나 분자들 의 결합환경을 알 수 있는 XPS 분석은 아주 유용하다. 실리콘 웨이퍼 위에 증착한 $\mathrm{ZnO}$ 박막의 경우 열처리에 의해서 $33^{\circ} \sim 34^{\circ}$ 근처에서 peak이 관찰되며, 결정성이 우 수해졌다. $\mathrm{SiO}_{2} / \mathrm{Si}$ 기판 위에서 $\mathrm{ZnO}$ 박막을 증착 할 경우 $\mathrm{XRD}$ 의 $33^{\circ} \sim 34^{\circ}$ 근처에서 픽이 관찰되지 않았으며, 산소 의 유량을 다양하게 하여 $\mathrm{SiO}_{2} / \mathrm{Si}$ 기판 위에 제작한 $\mathrm{ZnO}$ 박막을 열처리를 하여 계면에서 발생하는 결함으로써 metal oxygen( $\mathrm{Zn}$ interstitial), 산소공공(oxygen vacancy), $\mathrm{OH}$ 결함의 발생원인과 결정성에 대하여 조사였다. $\mathrm{ZnO}$ 박 막의 결정성이 증가하면 $\mathrm{XRD}$ 분석에서 신호 성분의 peak의 강도가 높아졌으며, XPS 분석에 의하면 결합에 너지가 높은 방향으로 화학적 이동을 하는 것을 확인하 였다. 또한 산소공공과 관련된 peak이 증가하였다. 하지 만 결정성이 떨어지면서 metal oxygen(Zn interstitial)의 peak이 증가하면서 XRD나 XPS 분석에서 신호 성분의 peak이 강도가 낮아지고 결합에너지가 낮은 방향으로 이 동하였다. 산소의 유량이 $50 \mathrm{sccm}$ 인 $\mathrm{ZnO}$ 에서 열 처리 후 비정질 특성이 나타나는 것은 XRD에 분석 후 (103)면 에서 peak이 나타나지 않는 것으로부터 비정질 임을 알 수 있다. 따라서 $\mathrm{ZnO}$ (103)면은 산소공공과 관련된 결 정면이며, 이온화에 따른 metal oxygen(Zn interstitial)에 의한 결함의 효과를 확인할 수 있는 결함 면임을 알 수 있다.

\section{References}

1. Hee Yeon Yang, Young Soo No, Jin Young Kim, and Tae Whan Kim, Jap. J. Appl. Phys., 51, 06FG13 (2012).
2. M. S. Kim, K. G. Yim, D. Y. Kim, S. Kim, G. Nam, D. Y. Lee, S. O. Kim, J. S. Kim, J S. Kim, J. S. Son, and J. Y. Leem, Electron. Mater. Lett., 8, 75 (2012).

3. D. H. Lee, K. W. Kim, Y. S. Chun, S. S. Kim and S. Y. Lee, Curr. Appl. Phys., 12, 1586 (2012).

4. Jang-Yeon Kwon, Do-Joong Lee and Ki-Bum Kim, Electron. Mater. Lett., 7/1, 1 (2011).

5. H. Yanagi, T. Hase, S. Ibuki, K. Ueda and H. Hosono, Appl. Phys. Lett., 78, 1583 (2001).

6. Y. Ogo, H. Hiramatsu, K. Nomura, H. Yanagi, T. Kamiya, M. Kimura, M. Hirano and H. Hosono, Phys. Status Solidi A, 206, 2187 (2009).

7. Chun-Chieh Lo, Tsung-Eong Hsieh, Ceram. Inter., 38, 3977 (2012).

8. C. H. Ahn, Y. Y. Kim, D. C. Kim, S. K. Mohanta and H. K. Cho, J. Appl. Phys., 105, 013502 (2009).

9. J. S. Park, W. J. Maeng, H. S. Kim and J. S. Park, Thin Solid Films, 520, 1679 (2012).

10. S. W. Tsao, T. C. Chang, S. Y. Huang, M. C. Chen, S. C. Chen, C. T. Tsai, Y. J. Kuo, Y. C. Chen, W. C. Wu, Solid-State Electron., 54, 1497 (2010).

11. S. Fernandez, A. Martinez-Steele, J. J. Gandia, F. B. Naranjo, Thin Solid Films, 517, 3152 (2009).

12. H. Hosono, J. Non-Cryst. Solids, 352, 851 (2006).

13. Y. S. Choi, J. W. Kang, D. K. Hwang and S. J. Park, IEEE Trans. Electron. Devices, 57, 26 (2010).

14. Y. Liu, C. R. Gorla, S. Liang, N. Emanetoglu, Y. Lu, H. Shen and M. Wraback, J. Electron. Mater., 29, 69 (2000).

15. Oleg Mitrofanov and Michael Manfra, J. Appl. Phys., 95, 6414 (2004). 